\title{
VITA ACTIVA E DIREITO DE RESISTÊNCIA: A NECESSIDADE DE SER AÇÃO
}

\author{
VITA ACTIVA Y DE DERECHO DE RESISTENCIA: LA NECESIDAD DE SER \\ ACCIÓN
}

\author{
Gustavo Dantas Carvalho ${ }^{1}$ \\ Andréa Galvão Rocha Detoni ${ }^{2}$
}

\section{RESUMO}

O artigo analisa a temática da condição humana teorizada por Hannah Arendt em consonância com o direito de resistência ao estado de exceção à luz da compreensão de Giorgio Agamben. Exemplifica-se o estudo com a questão da reformulação do ensino nas escolas públicas de São Paulo, elaborada em 2015, e a crise do sistema carcerário nacional. São feitas considerações acerca da necessidade de reação da sociedade civil em relação às questões complexas que a rodeiam. Utilizou-se o método dedutivo, com a revisão bibliográfica e a análise de dispositivos legais servindo de base para o presente estudo.

Palavras-chave: Vita activa, Ação, Direito de resistência

\begin{abstract}
El artículo analiza la cuestión de la condición humana teorizada por Hannah Arendt en consonancia con el derecho a la resistencia al Estado de Excepción en la visión del Giorgio Agamben. La reformulación de la educación en las escuelas públicas de São Paulo, redactada en 2015, y la crisis nacional del sistema penitenciario son también abordadas. Son hechas consideraciones sobre la necesidad de reacción de la sociedad civil en relación con las cuestiones complejas que la rodean. Se utilizó el método deductivo, con la revisión de la literatura y el análisis de las disposiciones legales.
\end{abstract}

Keywords: Vita activa, Acción, Derecho de resistencia

\footnotetext{
1 Mestrando em Constitucionalização do Direito pela Universidade Federal de Sergipe - UFS, Sergipe, (Brasil). Defensor Público do Estado de Sergipe, (Brasil).E-mail: gdcarvalho@globo.com

${ }^{2}$ Graduada em Direito pela Universidade Federal da Bahia - UFBA, Bahia, (Brasil). Analista Judiciária pelo Tribunal Regional do Trabalho da 20ª Região, Bahia, (Brasil). E-mail: andreagrdetoni@ gmail.com
} 


\section{INTRODUÇÃO}

O presente artigo tem o objetivo de analisar a condição humana, especificamente o que Hannah Arendt explica como vita activa e a resistência ao estado de exceção no conceito de Giorgio Agamben, abordando a temática em relação à realidade brasileira, especialmente no que tange ao plano de reformulação das escolas de São Paulo e ao sistema carcerário.

\section{INTRODUÇÃO CONCEITUAL: VITA ACTIVA}

Em 1958, foi publicado o livro A Condição Humana, de Hannah Arendt. Neste trabalho, Arendt procura expor um apanhado histórico da atividade humana, desde a Grécia antiga até o mundo moderno.

Especificamente no capítulo 5, denominado "A Vida Ativa e a Era Moderna", Hannah Arendt leciona que, ao se referir ao termo vita activa, ela busca designar três atividades fundamentais, quais sejam: o labor, o trabalho e a ação.

Esses três conceitos são especialmente trabalhados, pois, para a autora, eles são fundamentais, uma vez que correspondem às condições básicas da vida humana.

Inicialmente, labor é a atividade que corresponde ao processo biológico do corpo humano, cujo crescimento, metabolismo e envelhecimento estão diretamente ligados às necessidades vitais da vida. Para Hannah Arendt, a condição humana do labor é a própria vida.

Trabalho, no conceito fornecido pela autora em debate, é a atividade que corresponde à condição artificial da vida humana. É o trabalho que altera o ambiente natural, fornecendo um mundo artificial, em que todas as vidas individualmente consideradas estão incluídas, e que está fatalmente destinado a transcender a existência de cada um. Conclui Arendt que o trabalho é mundano.

Ação, por sua vez, é a única atividade desenvolvida diretamente entre homens, sem a intermediação da fabricação. Para Hannah Arendt, a ação corresponde à condição 
humana da pluralidade, uma vez que a humanidade, e não um homem individualmente considerado, vive e habita o mundo em que vive.

Já que todos os aspectos da condição humana estão, de alguma forma, relacionados à política, é a pluralidade a condição essencial de toda a vida política.

Arendt defende que, se os homens fossem repetições reprodutivas do mesmo modelo, cuja natureza ou essência fosse à mesma para todos, a ação seria desnecessária, pois é a pluralidade de condição humana que gera a diversidade nas pessoas e a necessidade de cada um de se expressar de forma diferente, exprimindo as suas necessidades através do discurso.

Todas as três atividades (labor, trabalho e ação) estão diretamente relacionadas à condição mais geral da vida humana, qual seja, o nascimento e a morte, a natalidade e mortalidade. O labor assegura a vida das espécies; o trabalho (e o seu produto) gera a durabilidade da produção humana; a ação, por sua vez, cria as condições para a lembrança do homem na história.

Para Hannah Arendt, a vita activa consiste no mundo de coisas produzidas pela atividade humana, mas aquilo que somente poderia ter sido criado pela vita activa constantemente condiciona os humanos que o criaram.

Os homens constantemente criam as próprias condições em que a origem humana e a sua variabilidade possuem o mesmo poder condicionante das coisas naturais.

As condições da existência humana (a vida, a natalidade e a mortalidade, a pluralidade) não explicam o que nós somos ou quem somos pelo simples fato de que elas não nos condicionam de forma absoluta.

Celso Lafer (1988, p. 214) ensina que Hannah Arendt analisa a vita activa na perspectiva da ação:

A ação contrasta com o labor e o trabalho por não ser nem consumo rapidamente metabolizado pela vida, nem trabalho que dura. Ação também não é obra de arte, cuja característica, enquanto trabalho, é a durabilidade. Ação, temporalmente, é passagem. Ela se recupera através da reminiscência. Daí a interligação entre o poder e a autoridade, na 
medida em que esta é memória compartilhada de feitor e acontecimentos do agir conjunto.

Apresentada esta breve análise das ideias de Hannah Arendt, necessário se faz introduzir as ideias de Giorgio Agamben.

\section{INTRODUÇÃO CONCEITUAL: ESTADO DE EXCEÇÃO E RESISTÊNCIA}

Giorgio Agamben, em sua obra Estado de Exceção, busca demonstrar que a normalidade institucional vem sendo substituída por um novo paradigma: o estado de exceção. Mas qual seria o significado dessa expressão criada por Carl Schmitt em 1921? Certamente essa não é uma pergunta fácil.

Para Schmitt, "o soberano decide o que é estado de exceção" (2006, p. 7). Estado de sítio, estado emergencial, estado de necessidade e martial law são algumas expressões utilizadas para tentar elucidar o significado do estado de exceção que, em verdade, representa uma situação na qual há suspensão da ordem jurídica anteriormente estabelecida, a fim de combater o inimigo. No estado de exceção, há nítida diferenciação entre direito e estado.

De acordo com Agamben, "o estado de exceção apresenta-se como a forma legal daquilo que não pode ter forma legal” (2004, p. 12), sendo que o estado de exceção moderno é uma "tentativa de incluir na ordem jurídica a própria exceção" (2004, p. 42).

Apesar de o próprio autor reconhecer a falta de uma teoria do estado de exceção (AGAMBEN, 2004, p. 11), pode-se dizer que o estado de exceção ocorreria quando se suspende a aplicação de uma ordem jurídica para que outra seja implantada, surgida através de um combate a um estado de necessidade, constituindo "um patamar de indeterminação entre democracia e absolutismo" (AGAMBEN, 2004, p. 13).

O discurso utilizado no estado de exceção prega a existência de uma ameaça que precisa ser combatida, um inimigo que precisa ser eliminado. Atualmente, o grande perigo vivenciado pela sociedade global é a constante troca e produção de novos inimigos. 
Para se manter politicamente, faz-se necessário decidir primeiramente quem é o inimigo, sendo o binômio proteção/obediência usado para a manutenção do poder. Quando um inimigo é eliminado, a solução é escolher outro inimigo e colocá-lo no centro de discussão.

No momento atual, o nacionalismo exacerbado aponta como inimigo o estrangeiro, sendo o combate ao terrorismo um discurso empregado para esconder verdadeiros interesses políticos e econômicos existentes.

Um dos fatores que o Agamben defende como causa para o estado de exceção é a erosão do Poder Legislativo (2004, p. 19), que, atualmente, frequentemente se limita a "ratificar disposições promulgadas pelo executivo sob forma de decretos com força-de-lei".

No Brasil, percebe-se a ocorrência desse fenômeno na quantidade de Medidas Provisórias editadas pelo Poder Executivo. A partir da Emenda Constitucional n. 32, de 11 de setembro de 2001, já foram editadas 721 medidas provisórias ${ }^{3}$.

Outra característica apontada é a "abolição provisória da distinção entre o Poder Legislativo, Executivo e Judiciário" (AGAMBEN, 2004, p. 19), o que demonstra a tendência de o estado de exceção se transformar em prática duradoura de governo.

Agamben ainda destaca que (2004, p. 63), na concepção de Carl Schmitt, o estado de exceção "é a abertura de um espaço em que a aplicação e norma mostram sua separação e em que uma pura força de lei realiza (isto é, aplica desaplicando) uma norma cuja aplicação foi suspensa".

Para Agamben (2004, p. 14), o estado de exceção representa um perigo de eliminação do estado jurídico do cidadão. No Estado Nazista, por exemplo, assim que Hitler assumiu o poder, ele instituiu o Decreto para a proteção do povo e do Estado que expressamente suspendia os artigos da Constituição de Weimar relativos às liberdades individuais.

\footnotetext{
${ }^{3}$ Dados verificados em 07 de abril de 2016. A Medida Provisória 721 foi publicada no dia 30 de março de 2016.
} 
Diante desse contexto, surge o direito de resistência ao estado de exceção, que visa mudar a cruel realidade fática construída pelo estado de exceção.

Segundo Noberto Bobbio (2004, p. 60), a resistência, enquanto contrária à obediência, "compreende todo comportamento de ruptura contra a ordem constituída, que ponha em crise o sistema pelo simples fato de produzir-se, como ocorre num tumulto, num motim, numa rebelião, numa insurreição, até o caso limite da revolução".

Sobre esse tema (direito de resistência), Agamben ensina (2004, p. 23) que em algumas Constituições, como a da República Federal Alemã, está explicitado o direito de resistência. Diz a Lei Fundamental Alemã:

Artigo 20

[Princípios constitucionais - Direito de resistência]

- A República Federal da Alemanha é um Estado federal, democrático e social.

- (2) Todo o poder estatal emana do povo. É exercido pelo povo por meio de eleições e votações e através de órgãos especiais dos poderes legislativo, executivo e judiciário.

- (3) O poder legislativo está submetido à ordem constitucional; os poderes executivo e judiciário obedecem à lei e ao direito.

- (4) Contra qualquer um, que tente subverter esta ordem, todos os alemães têm o direito de resistência, quando não houver outra alternativa.

$\mathrm{Na}$ atual Constituição italiana, por sua vez, havia um projeto de artigo o qual expressamente mencionava que, além de ser direito, o direito de resistência à opressão é um dever do cidadão nas hipóteses em que os poderes públicos violam as liberdades fundamentais.

Ocorre que esse artigo vanguardista, que buscava reforçar o manto protetivo dos direitos fundamentais dos cidadãos italianos, não foi aprovado na redação final da Carta italiana, impedindo o avanço dessa temática.

Agamben (2004, p. 41) defende que o estado de necessidade justificaria a resistência ao estado de exceção, uma vez que "a necessidade não é fonte de lei e tampouco suspende, 
em sentido próprio, a lei; ela se limita a subtrair um caso particular à aplicação literal da norma".

O tema da resistência à opressão também é tratado por Celso Lafer (1988, p. 190), que ensina que "o direito de resistência é, portanto, a consequência de uma crise no estado da sociedade civil, que fere a liberdade tornando possível a reversão provisória ao estado de natureza".

É nesse contexto de crise no estado da sociedade civil que se pretende trabalhar no presente artigo os fatos ocorridos no segundo semestre de 2015 nas escolas públicas de São Paulo e as rebeliões acontecidas nos presídios e delegacias no Brasil, analisando-os em conjunto com as ideias de Giorgio Agamben e Hannah Arendt apresentadas acima.

\section{O PLANO DE REFORMULAÇÃO DAS ESCOLAS DE SÃO PAULO}

Em setembro de 2015, o governador do estado de São Paulo anunciou que reformularia as escolas públicas estaduais, eliminando a possibilidade de uma escola abranger mais de um ciclo de ensino, ou seja, alunos do "ensino fundamental 1" não estudariam na mesma escola em que estudam alunos do "ensino fundamental 2" e de alunos do ensino médio.

A justificativa governamental era de que tal medida aumentaria a qualidade do ensino e evitaria que, por exemplo, um aluno de seis anos frequentasse a mesma unidade de um adolescente de 17 anos.

Ocorre que o efeito prático da medida seria o remanejamento de cerca de 311.000 estudantes com o fechamento de aproximadamente 94 instituições de ensino, segundo dados da Secretaria de Estado da Educação, que passariam a ter de se deslocar para escolas mais distantes de suas casas, sem que houvesse qualquer melhora sensível na qualidade do ensino prestado pelo Estado.

Diante dessa situação, inicialmente os sindicatos de professores protestaram, mas não foram ouvidos. Consequentemente, alunos fizeram manifestações buscando a reavaliação do programa, mas não foram atendidos. Por fim, alunos, pais e professores 
ocuparam as escolas estaduais, resistindo ao programa governamental. Após alguns dias de conflito e com alguma dose de violência estatal, o programa foi suspenso.

Os fatos ocorridos foram amplamente divulgados através das redes sociais e também não escaparam do olhar da imprensa, inclusive internacional, que repercutiu o assunto em diversas matérias jornalísticas.

A classe artística se manifestou através de uma canção denominada "O trono do estudar", composta por Dani Black e gravada por diversos nomes da música brasileira, como Chico Buarque, Dado Villa-Lobos, Zélia Duncan, Paulo Miklos e outros ${ }^{4}$.

\section{A REALIDADE CARCERÁRIA NO BRASIL}

O cenário carcerário brasileiro é um dos problemas que mais repercutem na realidade nacional, sendo tal perturbação social fato público e notório. Hiperencarceramento, condições carcerárias precárias e ausência de integração social do preso são problemas explícitos e de conhecimento manifesto.

Vale destacar que o Relatório Nacional de Informações Penitenciárias, elaborado em junho de 2014 pelo Ministério da Justiça, além de confirmar a realidade carcerária acima mencionada, anuncia a necessidade de criação de alternativas penais e de gestão de problemas ligados à superlotação dos presídios, a fim de promover a humanização das condições carcerárias e a inclusão social. Assim, o apoio à gestão dos serviços penais e a modernização do sistema penitenciário nacional são indispensáveis no desempenho desta tarefa.

\footnotetext{
${ }_{4}$ Ninguém tira o trono do estudar, ninguém é o dono do que a vida dá Ninguém tira o trono do estudar, ninguém é o dono do que a vida dá $\mathrm{E}$ nem me colocando numa jaula, porque sala de aula essa jaula vai virar E nem me colocando numa jaula, porque sala de aula essa jaula vai virar A vida deu os muitos anos da estrutura, do humano à procura do que Deus não respondeu Deu a história, a ciência, arquitetura, deu a arte, deu a cura e a cultura pra quem leu Depois de tudo até chegar neste momento, me negar conhecimento é me negar o que é meu Não venha agora fazer furo em meu futuro, me trancar num quarto escuro e fingir que me esqueceu de vocês vão ter que acostumar. Ninguém tira o trono do estudar, ninguém é o dono do que a vida dá Ninguém tira o trono do estudar, ninguém é o dono do que a vida dá $E$ nem me colocando numa jaula, porque sala de aula essa jaula vai virar E nem me colocando numa jaula, porque sala de aula essa jaula vai virar. E tem que honrar e se orgulhar do trono mesmo, e perder o sono mesmo pra lutar pelo o que é seu Que neste trono todo ser humano é rei, seja preto, branco, gay, rico, pobre, santo, ateu Pra ter escolha, tem que ter escola, ninguém quer esmola, e isso ninguém pode negar Nem a lei, nem estado, nem turista, nem palácio, nem artista, nem polícia militar vocês vão ter que engolir e se entregar ninguém tira o trono do estudar.
} 
No intuito de promover melhorias no sistema prisional brasileiro, foram idealizadas as audiências de custódia, em estrita articulação com os órgãos do sistema de justiça criminal, através de um acordo de Cooperação entre o Ministério de Justiça e o Conselho Nacional de Justiça - CNJ, que consiste na garantia da rápida apresentação da pessoa presa a um juiz nos casos de prisão em flagrante. Durante as mencionadas audiências, são ouvidas manifestações da Defensoria Pública, do Ministério Público ou do advogado da pessoa presa e o juiz pode aferir eventuais ocorrências de torturas e maus-tratos e averiguar a legalidade e a necessidade da prisão.

Entretanto, o Relatório do Infopen (sistema de informações estatísticas do sistema penitenciário brasileiro), de junho de 2014, revela fatos alarmantes, quais sejam: o crescimento acelerado da população carcerária brasileira, uma realidade diversa daquela vivenciada nos países de maior contingente prisional do mundo; a ocupação de presos condenados na maior parte dos estabelecimentos destinados a presos provisórios (84\%) e a taxa de ocupação dessas vagas (1,9 vagas de presos por média); a maioria dos presos provisórios estão detidos por prazo superior à duração razoável do processo $(60 \%$ estão custodiados há mais de 90 dias) e há superlotação em 63 estabelecimentos prisionais, abrigando 4 ou mais pessoas por vaga de preso.

De acordo com o mencionado relatório, a taxa de ocupação média dos estabelecimentos carcerários no Brasil é de $161 \%$, ou seja, em um ambiente preparado para acolher 10 presos existem aproximadamente 16 pessoas encarceradas. A gravidade da situação nacional é a quinta pior no mundo. Filipinas, Peru, Paquistão e Irã conseguem apresentar taxas de ocupação carcerária ainda piores: 316\%, 223\%, 177\% e 161,20\%, respectivamente.

O Internacional Prison Studies, por sua vez, informa que o Brasil está no $47^{\circ}$ lugar no ranking mundial de taxa de ocupação carcerária, possuindo uma taxa de ocupação de $153.9 \%$ nos estabelecimentos prisionais ${ }^{5}$.

5 Dados disponíveis em: <http://www.prisonstudies.org/highest-to-lowest/occupancy-level? field_region_taxonomy_tid=All>. Acesso em: 05 jan. 2016. 
Além dos mencionados dados, o relatório em tela traz outras informações como o número de estabelecimentos carcerários no Brasil que possuem local para revista íntima e acessibilidade para presos com deficiência; o número de unidades que têm módulos de saúde e profissionais da saúde; unidades com e sem sala de aula etc. As aludidas informações reforçam o triste cenário carcerário nacional e demonstram que o sistema carcerário e a prisão em si são a maior pena para o preso no Brasil, e não a liberdade cerceada propriamente dita.

Diante desse infeliz contexto, inúmeras rebeliões de presos ocorreram ao longo da história nacional. Os motins são utilizados como ferramentas pelos presos para o alcance de melhores condições carcerárias. A título de exemplo, serão citadas algumas rebeliões ocorridas recentemente.

Em junho de 2015, o presídio de Governador Valadares/MG foi palco de um uma rebelião. Naquela ocasião, o estabelecimento prisional em tela tinha capacidade para 290 presos e abrigava 800 custodiados.

A suspensão de visitas de parentes e entrega de alimentos, roupas e produtos de higiene aos presos, assim como a hiperlotação, foram os motivos das rebeliões de presos ocorridas em agosto de 2015 em duas delegacias da cidade de Aracaju/SE.

Em outubro de 2015, presos iniciaram rebelião na cidade de Teófilo Otoni/MG, sob a alegação de que eles estavam distantes dos seus familiares (os presos que iniciaram o motim eram originários do presídio de Governador Valadares/MG). Durante esse mesmo mês, houve uma rebelião na penitenciária estadual de Londrina, sendo motivada pela superlotação da penitenciária (1140 pessoas presas em um local projetado para 928 pessoas) e pela necessidade de revisão das penas.

\section{A RESISTÊNCIA DA SOCIEDADE CIVIL COMO AÇÃO}

Conforme exposto acima, na concepção arendtiana a ação é o aspecto da condição humana que reflete a intersubjetividade, sendo revelada através das interações humanas. Nesse contexto, as atitudes dos estudantes que ocuparam as escolas como forma de 
resistência à previsão legal geraram um reflexo imaterial, mas inegavelmente fixado na história como condição humana dos sujeitos.

São muitos os fundamentos da resistência à lei considerada violadora de uma ordem a qual, ainda que numa perspectiva profana, seja considerada naturalmente justa. Os fundamentos filosóficos jusnaturais estão presentes já na Antiguidade Clássica.

Com efeito, em Antígona, Sófocles trata do conflito humano entre respeitar a lei pública da autoridade ou o que impõe a lei divina, considerada, aqui, a perspectiva mundana do que é justo.

Antígona é levada a julgamento acusada de ter infringido a lei positivada que proibia a qualquer da cidade dar sepultura Polinice, irmão de Antígona. Diante dessa situação, Antígona questiona a ordem posta pelo Rei, reclamando direito sobre o corpo do irmão e resistindo à determinação normativa do Estado, sob o argumento de que ela resulta do arbítrio de um governante e que não foi promulgada pelos Deuses.

Antônio Carlos Wolkmer (2005, p. 4) ensina que Antígona representa o "símbolo de um humanismo de resistência".

Da mesma forma que Antígona resistiu à determinação legal (diga-se, através da ação de sepultar o seu irmão), os estudantes do estado de São Paulo, entendendo injusta a norma que estabeleceu o remanejamento deles, resistiram ao ato normativo emanado do Governo do Estado de São Paulo.

Na perspectiva de Giorgio Agamben (2004, p. 24), o direito à resistência funda-se no fato de que "o âmbito do direito excede a norma", uma vez que, segundo o autor, "tanto no direito de resistência quanto no estado de exceção, o que realmente está em jogo é o problema do significado jurídico de uma esfera de ação em si extrajurídica".

O direito de resistência é reflexo do próprio sentimento ético que consegue distinguir o que é justo e correto em uma dada situação, em um dado contexto. Através do exercício do direito de resistência, o homem explora a sua própria possibilidade ou potência. 
$\mathrm{Na}$ ótica de Giorgio Agamben, conforme se pode extrair do livro A comunidade que vem (2013, p. 45), somente uma ética pode existir e, diante disso, cabe ao homem explorar a sua existência como possibilidade ou potência em busca da efetivação da ética.

Nas palavras de Agamben (2013, p. 45):

Isso não significa, todavia, que o homem não seja nem tenha que ser alguma coisa, que ele seja simplesmente entregue ao nada e possa, portanto, a seu livre arbítrio decidir ser, estabelecer ou não estabelecer este ou aquele destino (niilismo e decisionismo se encontram nesse ponto) Há, de fato, algo que o homem é e tem de ser, mas este algo não é uma essência, não é, aliás, propriamente uma coisa: é o simples fato da própria existência como possibilidade ou potência. Mas, precisamente por isso, tudo se complica, precisamente por isso a ética se torna efetiva.

Para o mencionado autor, o único mal consiste "no decidir permanecer em débito com o existir, de apropriar-se da potência de não ser como de uma substância ou fundamento exterior à existência" (2013, p. 46). O homem precisa agir e explorar a sua potencialidade ou potência, exercendo o direito de resistência nas situações que exijam tal ação.

Já no livro $O$ mistério do mal, Agamben elucida que é inútil achar que se pode enfrentar a crise das sociedades por meio somente da atuação dos poder judiciário, pois "uma crise que investe a legitimidade não pode ser resolvida somente no plano do direito". A pretensão do direito de legislar sobre tudo implica na perda da legitimidade substancial (2015, p. 11).

Assim, independentemente de previsão expressa que dê embasamento ao direito de resistência, os homens precisam manter acessa a chama da justiça e lutar pelos seus direitos inatos, seguindo sempre o sentimento ético.

Nesse sentido, impende transcrever as palavras de Agamben acerca do tema (2015, p. 11), in verbis:

As instituições de uma sociedade só continuarão vivas se ambos os princípios (que em nossa tradição também receberam o nome de direito natural e direito positivo, de poder espiritual e poder temporal ou, em Roma, de auctoritas e potestas) se mantiverem presentes e nelas agirem, sem nunca pretender que coincidam. 
$\mathrm{Na}$ análise arendtiana, "todos os aspectos da condição humana têm alguma relação com a política" (2007, p. 15), mas a ação como "condição humana da pluralidade" é o elemento da vita activa capaz de promover a transformação da sociedade.

É preciso destacar que o direito de resistência também pode ser vislumbrado através de um atuar pacífico e aparentemente neutro. Não obstante essa afirmação possa parecer paradoxal, a leitura do livro O que resta de Auschwitz, de Giorgio Agamben, revela que a luta pela sobrevivência de muitos judeus no mencionado campo de concentração para dar ao mundo o testemunho da barbárie vivenciada naquele centro de horror representa uma ação em busca de mudança.

Tentar sobreviver, lutar até o final para conseguir testemunhar os horrores, é um agir, mesmo que o empenho seja aparentemente em vão ante incontáveis mortes. Diante de qualquer situação, inclusive naquela em que o homem é despido da sua dignidade, destituído de condições e direitos mínimos (vida nua), é preciso agir, explorando a potência e a possibilidade que lhe são factíveis.

Entender esse aparente paradoxo não é uma tarefa fácil, mas é preciso compreender que a passividade pode estar intimamente vinculada com o respeito a nós mesmos. De acordo com as lições de Agamben (2008, p. 114), “é claro que passividade não significa receptividade, o mero fato de sermos afetados por um princípio externo".

Nesse sentido, a ocupação das escolas estaduais se fundamentou na perspectiva jusnaturalista pela qual o direito ao ensino público de qualidade excede o âmbito da norma estabelecida pelo Estado, tendo sido estimulada pela ação, como reflexo da resistência, em detrimento da passividade.

Segundo leciona Celso Lafer (1988, p. 188), no jusnaturalismo moderno, em razão do individualismo que o permeia, "a ênfase no que diz respeito ao tema da resistência desloca-se dos deveres impostos pelo Direito Natural como um direito objetivo e dado a garantir a eticidade da Política, para os direitos subjetivos inatos dos indivíduos”.

Numa análise positivista, o direito à educação, analisado agora na perspectiva individual, é garantido na Constituição Federal de 1988 como direito público subjetivo, 
constituindo dever do Estado a sua disponibilização (art. 205 e seguintes da Lei Fundamental de 1988).

Ainda que se entenda, defendendo o plano de remanejamento do ensino, que não seria violado o direito ao acesso à educação, pelo simples fato de se fechar diversas escolas, obrigando os estudantes se deslocarem para instituições mais distantes, já haveria violação, na forma de ilegalidade, à ordem jurídica, uma vez que o Estatuto da Criança e do Adolescente estabelece como direito de todas as crianças e adolescentes o "acesso à escola pública e gratuita próxima de sua residência" (art. 53, inciso V).

Ademais, a Lei de diretrizes e bases da educação nacional (Lei 9.394, de 20 de dezembro de 1996) estabelece que o dever do Estado com educação escolar pública será efetivado mediante a garantia de vaga na escola pública de educação infantil ou de ensino fundamental mais próxima de sua residência a toda criança a partir do dia em que completar quatro anos de idade (art. $4^{\circ}$, inciso X).

Nisso se demonstra a tentativa de implementação de um estado de exceção pelo Governo do Estado de São Paulo, uma vez que, utilizando-se da linguagem de Giorgio Agamben, o Poder Executivo estadual, por disposição normativa (na forma de decreto), buscou desaplicar a legislação federal que trata sobre a matéria, aplicando um conjunto de disposições violadoras da ordem jurídica, natural ou positivada.

No tocante às rebeliões de presos, observa-se que eles exerceram o direito de lutar por melhores condições carcerárias e a salvaguarda de direitos humanos. São ações organizadas que visam à promoção dos direitos fundamentais, representando também um exemplo de exercício do direito de resistência.

A prisão deveria implicar apenas na perda do direito de ir e vir do preso, todos os demais direitos da pessoa encarcerada são, em tese, mantidos. Afinal, o preso não deixa de ser humano, com necessário respeito à sua dignidade, ao adentrar em estabelecimento prisional.

A privação da liberdade do preso não pode impedir o exercício de direitos fundamentais, tais como direito à educação, saúde, a assistência social e trabalho, direitos salvaguardados no caput do artigo $6^{\circ}$ da Carta Magna. 
Ademais, a Constituição Federal expressamente assegura ao preso o respeito à integridade física e moral (artigo 5, XLIX); proíbe penas cruéis (artigo 5, XLVII, "e"); e garante o devido processo legal, proporcionando, consequentemente, o direito à revisão da pena (artigo $5^{\circ}$, LIV).

A Lei de Execuções Penais, por sua vez, estabelece que o Estado tem a obrigação de prestar ao preso assistência material; à saúde; educacional; jurídica; social e auxílio aos egressos.

Direitos não faltam aos presos, o que falta é o seu exercício. Promessas constitucionais e legais não podem ficar presas ao papel da Constituição e da Lei.

Seguindo-se a ideia apresentada por Norberto Bobbio em A era dos direitos (2004, p. 22), "o importante não é fundamentar os direitos do homem, mas protegê-los. Não preciso aduzir aqui que, para protegê-los, não basta proclamá-los". Ou seja, a proclamação dos direitos da população carcerária já está estabelecida, o que falta é colocá-las em prática, e, enquanto isso não ocorrer, faz-se necessário lutar por tais direitos.

\section{CONCLUSÃO}

Não obstante a atuação firme dos poderes estatais seja imprescindível para o enfrentamento das questões complexas que envolvem a sociedade, a solução para tais problemas não será encontrada apenas com políticas públicas. A história mostra que, embora o Estado seja o pacificador social por excelência, a sociedade não pode ser obediente demais diante das falhas, ilegalidades e atrocidades praticadas. É necessário agir, é necessário explorar todas as possibilidades e potências diante da conjuntura apresentada.

Assim, é preciso que os homens atuem em conjunto, em uma atividade que envolva a condição humana da pluralidade. É preciso que haja a ação à luz da teoria arendtiana.

Diante disso, o exercício do direito de resistência ao estado de exceção torna-se primordial, já que ele representa a própria ação dos homens em busca da única ética 
existente e da promoção da dignidade da pessoa humana. Trata-se, em verdade, de uma ação social organizada em prol da efetivação de tais direitos.

No presente artigo, foram tratados dois exemplos de direito de resistência exercidos no cenário nacional, quais sejam: a manifestação de alunos, professores e membros da sociedade civil contra o plano de reformulação das escolas de São Paulo e as rebeliões em presídios brasileiros com o intuito de melhorar as condições carcerárias.

A reformulação do ensino proposta pelo governo representaria o fechamento de aproximadamente 94 instituições de ensino no estado de São Paulo e os alunos passariam a ter de se deslocar para escolas mais distantes de suas residências, sem que isso refletisse na melhora do ensino prestado pelo Estado.

O protesto da sociedade paulistana teve consequências positivas para a comunidade, já que o governador do estado de São Paulo suspendeu a reorganização do ensino para o ano de 2016. Além disso, o mencionado agente político prometeu dialogar com as escolas acerca das reformulações do ensino no futuro.

No que toca à repercussão das rebeliões dos presos, faz-se necessário frisar que os aludidos motins ainda não conseguiram o resultado desejado, qual seja, a melhora do cenário prisional nacional. $\mathrm{O}$ sistema de informações estatísticas do sistema penitenciário brasileiro estampa a cruel realidade vivenciada por mais de 600 mil presos: os encarcerados brasileiros sobrevivem em condições subumanas.

À guisa de conclusão, pode-se dizer que é preciso agir e agir em conjunto, explorando a força que surge da ação exercida em pluralidade pelos homens, a fim de mudar a realidade e construir um mundo melhor. As pessoas não podem simplesmente aceitar tudo que é imposto pela tirânica conjuntura existente. As questões problemáticas não podem permanecer invisíveis aos olhos da sociedade.

\section{REFERÊNCIAS}

ALCKMIN publica decreto e avança na reforma dos ciclos da rede paulista. Folha de S.Paulo, São Paulo, 01 dez. 2015. Disponível em: 
<http://www1.folha.uol.com.br/educacao/2015/12/1713412- alckmin-publica-decreto-eavanca-na-reforma-dos-ciclos-da-rede-paulista.shtml>. Acesso em: 18 dez. 2015.

ALCKMIN publica decreto que revoga fechamento de escolas em São Paulo. Valor econômico, São Paulo, 05 dez. 2015. Disponível em: <http://www.valor.com.br/politica/4343458/alckmin- publica-decreto-que-revogafechamento-de-escolas-em-sao-paulo>. Acesso em: 19 dez. 2015.

BOBBIO, Noberto. A era dos direitos. Tradução de Carlos Nelson Coutinho. Rio de Janeiro: Elsevier, 2004.

BRASIL. Ministério da Justiça. Levantamento Nacional de Informações Penitenciárias. Disponível em: <http://www.justica.gov.br/noticias/mj-divulgara-novo-relatorio-do-infopennesta- terca-feira/relatorio-depen-versao-web.pdf> Acesso em: 27 dez. 2015.

GIORGIO. Agamben. A comunidade que vem. Tradução e notas de Cláudio Oliveira. Belo Horizonte: Autêntica Editora, 2013.

. O Estado de Exceção. Tradução de Iraci D. Poleti. 2. ed. São Paulo: Boitempo, 2004 (Estado de sítio).

. O mistério do mal. Bento XVI e o fim dos tempo. Tradução de Silvana de Gaspari e Patricia Peterle. São Paulo: Boitempo; Florianópolis: Editora UFSC, 2015.

. O que resta de Auschwitz: o arquivo e a testemunha (Homo Sacer III). Tradução de Selvino J. Assmann. São Paulo: Boitempo, 2008 (Estado de sítio).

HANNAH. Arendt. A condição humana. Tradução de Roberto Raposo. 10. ed. Rio de Janeiro: Forense Editora, 2007. 
HIGHEST to lowest: occupancy level (based on official capacity). Prision studies. Disponível em:<http://www.prisonstudies.org/highest-to-lowest/occupancy-level? field_region_taxonomy_tid=All>. Acesso em: 05 jan. 2016.

LAFER, Celso. A reconstrução dos direitos humanos: um diálogo com o pensamento de Hannah Arendt. São Paulo: Companhia das Letras, 1988.

MACHADO, Leandro. Promotoria e Defensoria entram com plano parar barrar plano de Alckmin. Folha de S.Paulo, São Paulo, 03 dez. 2015. Dispnível em: <http://www1.folha.uol.com.br/ educacao/2015/12/1714535-promotoria-e-defensoriaentram-com-acao-para-barrar-plano-de- alckmin.shtml>. Acesso em: 19 dez. 2015.

ORTELADO, Pablo. Brasil's students occupy their schools to save them. The New York Times, New York, 15 dez. 2015. Disponível em: <http://www.nytimes.com/2015/12/16/opinion/brazils- students-occupy-their-schools-tosave-them.html>. Acesso em: 20 dez. 2015.

SCHMITT, Carl. Teologia Política. Tradução de Elisete Antoniuk. Coordenação e Supervisão de Luiz Moreira. Belo Horizonte: Del Rey, 2006.

SCOLESE, Eduardo. Sob protestos, Alckmin suspende plano de reorganização das escolas. Folha de S.Paulo, São Paulo, 4 dez. 2015. Disponível em: <http://www1.folha.uol.com.br/educacao/2015/12/1714946-sob-protestos-alckminsuspende-plano-de-reorganizacao-de-escolas.shtml>. Acesso em: 19 dez. 2015.

SERRANO, Pedro Estevam. Um Estado marginal e sem educação. Carta Capital, São Paulo. Confiança, 15 dez. 2015. Disponível em: <http://www.cartacapital.com.br/educacao/um-estado- marginal-e-sem-educacao>. Acesso: 23 dez. 2015.

SÓFOCLES. Antígone. Tradução de J. B. de Mello e Souza. Clássicos Jackson. Vol. XXII. Disponível em: <http://www.ebooksbrasil.org/eLibris/antigone.html>. Acesso em: 3 dez. 2015. 
WOLKMER, Antonio Carlos. O Direito como expressão da natureza cósmica: Sófocles, Aristótles e Cícero. In: WOLKMER, Antonio Carlos (Org.). Fundamentos do Humanismo Jurídico no Ocidente. Barueri: Editora Manole, 2005, p. 1-13. 